\title{
Assessing the Impact of Ramadan Fasting on Pulmonary Function: Evidences from Healthy Young Adults
}

\author{
Thejaswi Dodderi ${ }^{1 *}$ and Rhea Philip ${ }^{2}$ \\ ${ }^{1}$ Assistant Professor, Nitte Institute of Speech and Hearing, India \\ ${ }^{2}$ MASLP student, Kasturba Medical College, India
}

Submission: August 28, 2018; Published: September 20, 2018

*Corresponding author: Thejaswi Dodderi, Assistant Professor (Grade-I), Nitte Institute of Speech and Hearing, Medical Sciences Complex, Nithyanandanagar Deralakatte, Mangaluru, India, Email: thejaswi07@gmail.com

\begin{abstract}
Followers of Islam annually perform fasting in the holy month of Ramadan. Literature suggests Ramadan fasting to receive health benefits. However, the effect of fasting has not been explored in the Indian community, where the fasting practices vary. In the present study, we aimed to measure the pulmonary function of individuals under Ramadan fasting. Thirty-seven healthy adults between 18-23 years participated. Twenty non-fasting and seventeen fasting healthy adults underwent spirometric tracings available in the Helios 401 spirometer. Individuals under fasting performed spirometry tracings across the $1^{\text {st }}$ week of fasting, last week of fasting and one week after breaking of fasting. Results indicated the pulmonary performance of fasting subjects during the $1^{\text {st }}$ week of fasting and last week of fasting to be poorer than non-fasting volunteers. Interestingly, after the one-week post breaking of fasting few parameters exhibited higher performance than the non-fasting volunteers. Multivariate analysis of variance suggests a statistically significant difference between non-fasting vs. $1^{\text {st }}$ week of fasting and non-fasting vs. last week of fasting at $\mathrm{p}<0.05$. Collectively, the present study concludes that fasting during the month of Ramadan improves the pulmonary function.

Keywords: Spirometry; Vital Capacity; Pulmonary function; Fasting; Post-effects
\end{abstract}

\section{Introduction}

Fasting designates complete and/or partial restrain from intake of oral feeds. In the holy month of Ramadan, about 400 million followers of Islam voluntarily forbid themselves in taking oral feeds [1]. Ramadan is observed as a mark of restrain and introspection. Universally, practitioners of Ramadan abstain from eating, drinking and other particular activity from sunrise till sunset, which approximates for 12 hours. Fasting is broken once before sunrise and another after sunset [2]. During this holy month the body physiology and cellular metabolism influences the body functions, and likely the speech sub-system [3]. Research pin points innumerable evidences of fasting leading to varied body weight, electrolyte levels, glucose absorption and physical activity [3]. Considering these critical issues, typically occurring on the 9th month of Islamic calendar and/ or during May-June, all health care professionals are advised to assess pulmonary function in their clinical practise during this time frame.

In the past several researchers have explored pulmonary functioning in individuals under fasting. In a cohort study on healthy adults results revealed statistically significant difference in vital capacity, forced vital capacity, peak expiratory force rate and maximum vital volume between 10 days before, during and 10 days after Ramadan recordings [4]. However, in another study no differences in spirometry tracings was observed in asymptomatic young adults vital capacity, peak expiratory force rate and body mass [5]. Studies on clinical population of asthma also revealed no significant impact in the degree of asthma while fasting [6]. These varying findings do not provide us with a clear clinical picture on the impact of fasting on pulmonary functioning. Moreover, there exists dearth of clinical research in India, a country which houses 100 million followers of Islam. Further, there exists difference in duration and practise of fasting because of differences in the season and geographical location of the country [7]. Apparently, these subtle changes make comparison between studies un-reliable and difficult to draw conclusions. Hence, the primary aim of the study was to observe effect of Ramadan fasting on pulmonary function in asymptomatic healthy young adults.

\section{Method and Materials}

Participants. Total of thirty-seven asymptomatic healthy young adults within the age range of 18-22 years (mean age $=20.4$ years) participated. Volunteers were divided into twenty non-fasting seventeen age and gender matched young adults under fasting. No volunteers reported any history of 
speech, neurological, pulmonary, cardiac problems and/or substance abuse. The inclusionary criteria considered for fasting volunteers were complete restrain from consuming food and water for continuous 12 hours (from sunrise till sunset).

Instrumentation. Helios 401 (RMS, Haryana, India) spirometer was used to assess pulmonary function. It is a hand-held apparatus consisting of a turbine transducer housed within the main unit and is connected to a detachable mouth piece. Pulses generated by the volunteers are picked up by the sensitive transducer amplifies and forwards the information to the Micro Controller.

Procedure. Spirometric tracings were performed in the Voice Laboratory of a multi-disciplinary teaching hospital. Volunteers completed the spirometry tracings seated comfortably on a chair with their foot placed firm on the ground. Daily calibration check was performed prior to data collection. Live demonstration of the manoeuvres was given by the clinician followed by hands on practice to all the volunteers. Spirometric tracing for fasting volunteers were performed across three sessions: 1st week of fasting, last week of fasting and one week after breaking of fasting. Disposable mouthpiece was attached to the rim of the hand piece and volunteers were directed to blow air from the mouth while maintaining a tight lip seal across the mouth piece. Following which Vital capacity (VC), Forced Vital Capacity (FVC), Inspiratory Capacity (IC), Inspiratory Reserve Volume (IRV), Expiratory Reserve Volume (ERV), Tidal Volume (TV), Total Inspiration Time (Ti) and Total Expiration Time (Te) data was tabulated. Statistical testing was performed by Statistical Package for the Social Sciences (Version 17).

Results

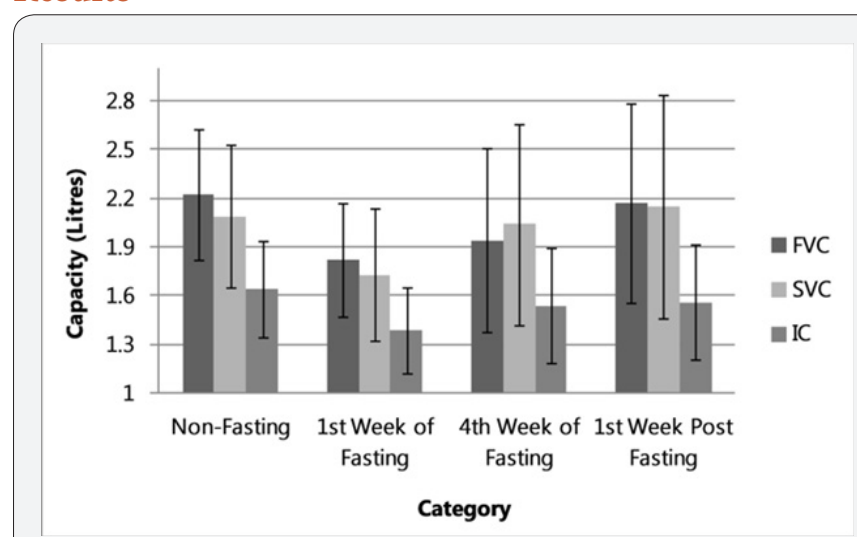

Figure 1: Descriptive statistics of FVC, SVC, and IC.

The results of present study, represented in Figures 1-3, suggest that non-fasting volunteers pulmonary functioning to be better than fasting volunteers. Comparing the volunteer's performance across different phases of fasting, 1st week of fasting had the poorest performance followed by 4 th week of fasting. Interestingly, post one week breaking of fasting few parameters exhibited higher performance than the non-fasting volunteers. Collectively, these results provide evidence on increased pulmonary function after fasting during month of
Ramadan. Multivariate analysis of variance with main effects of fasting as the variable between non-fasting and fasting volunteers suggested statistically significant difference for: non-fasting vs. 1st week of fasting for-FVC [F $(1,1.495)=10.512 ; p=0.003]$, SVC $[F(1,1.161)=6.6445 ; p=0.01]$, IC $[F(1,0.594)=7.388 ; p=0.01]$, IRV $[F(1,0.361)=5.223 ; p=0.02]$, and $\mathrm{Te}[\mathrm{F}(1,0.496)=3.969$; $\mathrm{p}=0.05]$ parameters; non-fasting vs. last week of fasting acrossFVC $[F(1,0.714)=3.050 ; p=0.05]$; and non-fasting vs. 1st week post breaking of fasting only for IRV $[F(1,0.251)=3.382 ; p=0.05]$. Repeated measures of analysis of variance were applied to observe main effects of fasting within volunteers under fasting. The results revealed no statistically significant difference at $\mathrm{p}>0.05$.

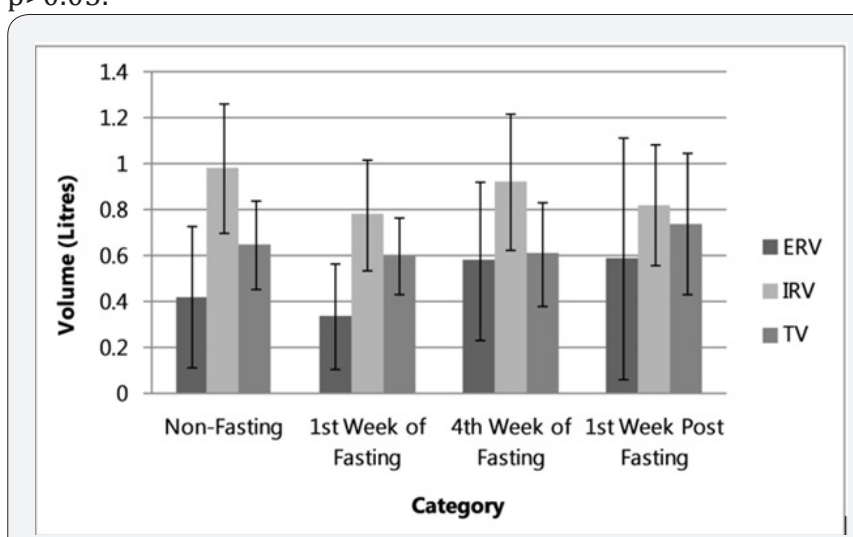

Figure 2: Descriptive statistics of ERV, IRV, and TV.

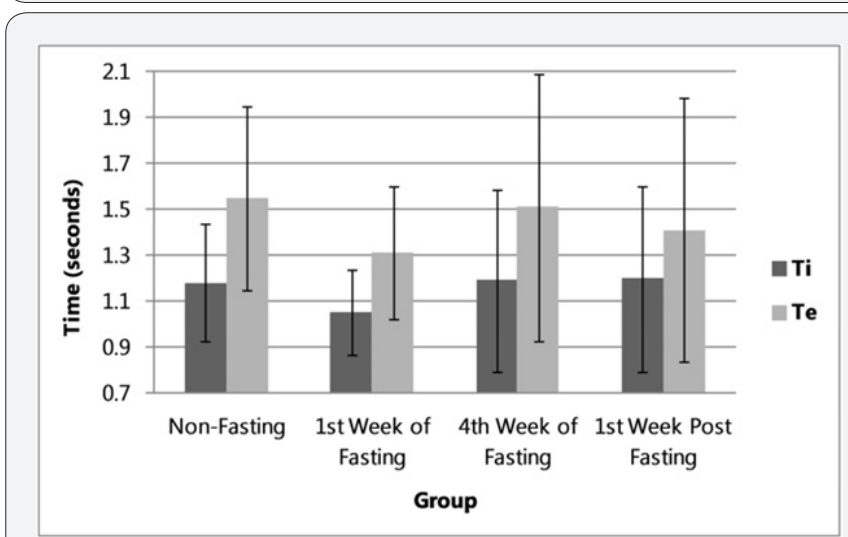

Figure 3: Descriptive statistics Ti and Te.

\section{Discussion}

In this study we aimed to investigate pulmonary function of individuals practicing fasting in the holy month of Ramadan. Comparing spirometric tracings between non-fasting vs fasting volunteers, the results suggest better pulmonary functioning in non-fasting volunteers and fasting volunteers catching up in the $1^{\text {st }}$ week post breaking of fasting. Reduced pulmonary functions during fasting could be due to varying physiological status of the fasting volunteers. Researchers have enumerated that reduced fluid content and electrolytes level are common during the initial stages of fasting [8]. This in-turn would have lead to dehydration and dryness of the respiratory tract. As a consequence, fasting volunteers may have had broncho-constriction, thereby acting 
as airway resistance and causing decreased pulmonary function. This is observable in the study results of 1 st week of fasting that revealed lower spirometry findings than non-fasting. Varying levels of stress, sleep changes, and fatigue are also contributing factors. Generally, fasting is broken early morning, before sunrise, within a particular time frame, followed by prayer. This reduces the overall duration of sleep and un-balances the natural sleep-wake-cycle in an individual. Although, lack of sleep maybe compensated during daylight, provided the subject does so, normal sleep-wake routine is disturbed [9]. Keeping this into account, the body may undergo series of stress and fatigue leading to volunteer's body functions not performing to their optimum level. These provide valuable information on changes noticed during last week of fasting may be as a result of continuous disturbed sleep in addition to altered body metabolism. Apparently, to overcome these challenges, one compromises their routine day-to-day physical activity. In addition, one consumes more nutritious food, during the first breaking of fasting, with high glucose content to conserve energy till next breaking of fasting. However, there exists large discrepancy in effect of these on body mass, wherein few studies supplement while other studies contraindicates [3,4]. Moreover, it becomes difficult for us to comment upon as the present study did not monitor the body mass during the course of the study.

In our study we also observed higher level of pulmonary function in fasting volunteers 1st week post breaking of fasting compared to non-fasting. This outperformance in some parameters can be due to possibility of increased levels of catecholamine - a neurotransmitter, which functions as a broncho-dilator and permits increased amount of air intake [4]. Additionally, flattening of diaphragm due to empty stomach can also add on to increased pulmonary function.

\section{Conclusion}

The study was undertaken to observe if there are any changes in the pulmonary function of healthy asymptomatic young adults due to fasting. Overall the results of descriptive statistics provide us evidence of reduced pulmonary function in fasting volunteers during $1^{\text {st }}$ week and last week of fasting, with increase in pulmonary function $1^{\text {st }}$ week post breaking of fasting. These changes give us much needed understanding of compromised airway functioning during holy month of Ramadan. These evidence can be used a red flags in identifying etiology behind subtle changes in the production of voice during the holy month of Ramadan. The study provides further scope for monitoring pulmonary function before initiating fasting and also document changes in the body mass. Long term effects of fasting on pulmonary function and other speech sub-systems can also be explored.

\section{Acknowledgement}

The authors place on record their heartfelt gratitude to the Director, Nitte Institute of Speech and Hearing, Mangaluru for permitting us to carry out this study. We also express our sincere thank you to all the participants for volunteering.

\section{References}

1. Rashed AH (1992) The fast of Ramadan. BMJ 304(6826): 521-522.

2. Ibrahim WH, Habib HM, Jarrar AH, Al Baz SA (2008) Effect of Ramadan fasting on markers of oxidative stress and serum biochemical markers of cellular damage in healthy subjects. Ann of Nutr Metab 53(3-4): 175-181.

3. Subhan MM, Siddiqui QA, Khan MN, Sabir S (2006) Does Ramadan fasting affect expiratory flow rates in healthy subjects? Saudi Medical Journal 27(11): 1656-1660.

4. Moosavi SAJ, Kabir A, Moghimi A, Chehrei A, Rad MB (2007) Evaluation of the effect of Islamic fasting on lung volumes and capacities in the healthy persons. Saudi Med J 28(11): 1666-1670.

5. Siddiqui QA, Sabir S, Subhan MM (2005) The effect of Ramadan fasting on spirometry in healthy subjects. Respirology 10(4): 525-528.

6. Norouzy A, Karimirad R, Sabety BZ, Amini M, Attaran D, et al. (2013) Effects of Ramadan fasting on spirometric values and clinical symptoms in asthmatic patients. Journal of Fasting and Health 1(1): 23-27.

7. Zadegan SN, Atashi M, Naderi GA, Baghai AM, Asgary S, et al. (2000) The effect of fasting in Ramadan on the values and interrelations between biochemical, coagulation and hematological factors. Ann Saudi Med 20(5-6): 377-381.

8. Sweileh N, Schnitzler A, Hunter GR, Davis B (1992) Body composition and energy metabolism in resting and exercising muslims during Ramadan fast. J Sports Med Phy Fitness 32(2): 156-163.

9. Ziaee V, Razaei M, Ahmadinejad Z, Shaikh H, Yousefi R, et al. (2006) The changes of metabolic profile and weight during Ramadan fasting. Singapore Med J 47(5): 409-414.

\section{Your next submission with Juniper Publishers} will reach you the below assets

- Quality Editorial service

- Swift Peer Review

- Reprints availability

- E-prints Service

- Manuscript Podcast for convenient understanding

- Global attainment for your research

- Manuscript accessibility in different formats

( Pdf, E-pub, Full Text, Audio)

- Unceasing customer service

Track the below URL for one-step submission https://juniperpublishers.com/online-submission.php 